\title{
Effects of thrombospondin-4 on pro-inflammatory phenotype differentiation and apoptosis in macrophages
}

\author{
Mohammed Tanjimur Rahman (1)', Santoshi Muppala', Jiahui Wu' ${ }^{1}$, Irene Krukovets', Dmitry Solovjev', \\ Dmitriy Verbovetskiy ${ }^{1}$, Chioma Obiako', Edward F. Plow ${ }^{1}$ and Olga Stenina-Adognravi (1)
}

\begin{abstract}
Thrombospondin-4 (TSP-4) attracted renewed attention recently as a result of assignment of new functions to this matricellular protein in cardiovascular, muscular, and nervous systems. We have previously reported that TSP-4 promotes local vascular inflammation in a mouse atherosclerosis model. A common variant of TSP-4, P387-TSP-4, was associated with increased cardiovascular disease risk in human population studies. In a mouse atherosclerosis model, TSP-4 had profound effect on accumulation of macrophages in lesions, which prompted us to examine its effects on macrophages in more detail. We examined the effects of A387-TSP-4 and P387-TSP-4 on mouse macrophages in cell culture and in vivo in the model of LPS-induced peritonitis. In tissues and in cell culture, TSP-4 expression was associated with inflammation: TSP-4 expression was upregulated in peritoneal tissues in LPS-induced peritonitis, and pro-inflammatory signals, INFY, GM-CSF, and LPS, induced TSP-4 expression in macrophages in vivo and in cell culture. Deficiency in TSP-4 in macrophages from Thbs $4^{-1}$ mice reduced the expression of pro-inflammatory macrophage markers, suggesting that TSP-4 facilitates macrophage differentiation into a pro-inflammatory phenotype. Expression of TSP-4, especially more active P387-TSP-4, was associated with higher cellular apoptosis. Cultured macrophages displayed increased adhesion to TSP-4 and reduced migration in presence of TSP-4, and these responses were further increased with P387 variant. We concluded that TSP-4 expression in macrophages increases their accumulation in tissues during the acute inflammatory process and supports macrophage differentiation into a pro-inflammatory phenotype. In a model of acute inflammation, TSP-4 supports pro-inflammatory macrophage apoptosis, a response that is closely related to their pro-inflammatory activity and release of pro-inflammatory signals. P387-TSP-4 was found to be the more active form of TSP-4 in all examined functions.
\end{abstract}

\section{Introduction}

Thrombospondin-4 (TSP-4) is a matricellular protein, one of the five members of thrombospondin family ${ }^{1,2}$. TSP-4 expression is low in adult tissues, but dramatically increases during tissue remodeling and regeneration. High levels of TSP-4 have been detected in remodeling and failing hearts ${ }^{3-7}$, several cancers ${ }^{8-13}$, and atherosclerotic lesions ${ }^{14}$. Recently, new functions have been

Correspondence: Olga Stenina-Adognravi (stenino@ccf.org)

'Department of Cardiovascular \& Metabolic Sciences, Cleveland Clinic, Cleveland, OH, USA

Edited by T. Kaufmann ascribed to TSP-4 in the cardiovascular system ${ }^{5-7,14-25}$, cancer $^{8-12,24-29}$, skeletal muscle ${ }^{30,31}$, and nervous system ${ }^{32-36}$, but effects of TSP-4 on cellular responses and the regulation of TSP-4 expression remain poorly understood. For example, with an exception of TGFbeta $^{25}$, stimuli inducing TSP-4 expression in tissues remain unknown. Although several cell surface receptors were shown to mediate TSP-4 effects ${ }^{14,24,32,37}$, signaling and regulation of intracellular processes by TSP- 4 have received only limited attention.

While TSP-4 is best known as a secreted extracellular matrix $(\mathrm{ECM})$ protein, it became clear that some of its

\section{(c) The Author(s) 2020}

(c) (i) Open Access This article is licensed under a Creative Commons Attribution 4.0 International License, which permits use, sharing, adaptation, distribution and reproduction cc) in any medium or format, as long as you give appropriate credit to the original author(s) and the source, provide a link to the Creative Commons license, and indicate if changes were made. The images or other third party material in this article are included in the article's Creative Commons license, unless indicated otherwise in a credit line to the material. If material is not included in the article's Creative Commons license and your intended use is not permitted by statutory regulation or exceeds the permitted use, you will need to obtain permission directly from the copyright holder. To view a copy of this license, visit http://creativecommons.org/licenses/by/4.0/. 
effects depend on its intracellular interactions: its binding to the ER lumenal domain of activating transcription factor $6 \alpha$ (Atf6 $\alpha)$ protects cardiomyocytes from injury caused by ER stress responses ${ }^{7}$. Thus, this protein exerts its effect in multiple complementary ways: by initiating intracellular signaling and transiting through secretory pathways $^{38}$, as well as by binding to its extracellular ligands and receptors upon secretion ${ }^{5,6,14,24,30,33,37,39-48}$.

Tissue remodeling, inflammation, and angiogenesis often occur simultaneously and are regulated by the same stimuli. We recently reported that TSP-4 promotes angiogen$\mathrm{esis}^{24,25}$ and vascular inflammation in a mouse atherosclerosis model ${ }^{14}$. These observations suggested that TSP-4 may play an important role in regulation of inflammation and inflammatory cell responses. In this study, we describe effects of TSP-4 and its common variant, P387-TSP-4, on macrophages. The P387-TSP-4 variant is associated with an increased risk of cardiovascular disease and myocardial infarction $^{15-22}$ and is more active than WT A387-TSP-4 in mediating cellular effects ${ }^{24,37,42,49}$. The region of TSP-4 molecule harboring P387 SNP appears to be important in regulation of many TSP-4 functions and was found to mediate the intracellular effects of TSP $-4^{50}$ and its effects in the nervous system ${ }^{32}$.

TSP-4 production by blood cells has not been reported to date. Here, we report several stimuli that induce or reduce TSP-4 production in macrophages. The effect of TSP-4 on macrophages has been examined in isolated macrophages and in LPS-induced peritonitis, an in vivo model of acute inflammation.

Macrophages play multiple roles in both the tissue homeostasis and inflammation, e.g., promote the initiation, progression, and healing of tissue injury; facilitate tissue remodeling associated with various pathologies; and participate in initiation and resolution of inflammation in tissues $^{51,52}$. Macrophages are a heterogeneous cell types with high plasticity and display a variety of phenotypes regulated by external stimuli, including the extracellular matrix $^{53}$. A continuum of phenotypes exists that can be pragmatically divided into pro-inflammatory and tissuerepair macrophages. Phenotypic polarization of macrophages is regulated by pro-inflammatory stimuli that include Toll-like receptor (TLR) ligands and IFNy, which induce pro-inflammatory phenotypes, and by antiinflammatory stimuli such as IL-4/IL13, immune complexes, the anti-inflammatory cytokines IL-10, and transforming growth factor- $\beta$ that induce tissue-repair phenotypes $^{54-57}$. Although the effects of microenvironment, including ECM proteins and matricellular proteins specifically, on phenotypic differentiation of macrophages are undeniable, they are still poorly understood. Here, we have uncovered previously unrecognized cellular mechanisms for regulation of phenotypes and functions of macrophages by TSP-4 and the P387-TSP-4 variant.

\section{Materials and methods \\ Animals}

Mice were of C57BL/6 background, 12-16 weeks of age, 30-35 g of body weight, and fed on regular chow diet. Both genders were used (there were no gender-specific differences). In total, 3-12 mice per group were used in in vivo experiments as indicated in the Figure legend, and the experiment was repeated three times. Thbs $4^{-1-}$ mice were described previously ${ }^{5,14,24,25,30}$, as were TSP-4P387KI mice ${ }^{24}$. Briefly, these mice express P387-TSP-4 under the endogenous TSP-4 gene promoter (only a fragment of DNA where the SNP was found was substituted). P387-TSP-4 is expressed in the same pattern as the naturally occurring A387 variant in WT mice by immunocytochemistry (data not shown). The KI mouse colony has been maintained for more than 10 years in C57Bl/6 background, and are periodically crossed with WT mice to avoid genetic drift. Also, the TSP-4-P387KI mice are genotyped to insure integrity of the line. The TSP-4-P387KI mice develop and reproduce normally, and do not have an overt phenotype without challenge. Control wild-type (WT) mice were from the same mouse colony as Thbs $4^{-1-}$ mice or P387-TSP-4-KI mice.

For experiments exclusively using WT mice, WT C57BL/6 mice were purchased from the Jackson Laboratories. Animals were housed in the AAALACapproved animal facilities of the Cleveland Clinic. Animal procedures were approved by the Institutional Animal Care and Use Committee of the Cleveland Clinic in agreement with the NIH Guide for Animal Use.

\section{LPS-induced peritonitis}

Mice were treated with intraperitoneal (IP) injection of lipopolysaccharide (LPS, $0.5 \mu \mathrm{g} / \mathrm{g}$, ThermoFisher) to induce peritonitis $72 \mathrm{~h}$ prior to isolation of peritoneal cells by lavage and resection of visceral peritoneum. Mouse peritoneal macrophages (MPM) were used directly for cell adhesion and migration experiments. mRNA was isolated from MPM and peritoneal tissue. Immunofluorescence was also done on peritoneal tissues. IP injection with PBS was used for the control groups of animals.

\section{Isolation and culture of primary macrophages}

Bone-marrow-derived macrophages (BMDM) were isolated from the hind leg tibia and femur of WT, Thbs $4^{-1-}$, or P387-TSP-4 KI mice. In each experiment, the bone marrow cells were collected from three individual mice without pooling, and differentiated into BMDM using $30 \mathrm{ng} / \mathrm{mL}$ M-CSF for 7 days. Each experiment (Western blot, qRT-PCR, adhesion assay, migration assay, cell survival, and cellular apoptosis) was conducted using macrophages from independent mice of the noted genotypes. All experiments were repeated at least three times. These cells were treated with $50 \mathrm{ng} / \mathrm{mL}$ GM-CSF, $50 \mathrm{ng} / \mathrm{mL}$ M-CSF, 
$40 \mathrm{ng} / \mathrm{mL}$ IL-4, $2000 \mathrm{IU} / \mathrm{mL}$ IFNy, $0.5 \mu \mathrm{g} / \mathrm{mL}$ LPS. Following stimulations, cells were analyzed by Western blot and quantitative RT-PCR for specific protein/gene expression patterns.

\section{Cell culture and cell lines}

Mouse macrophage cell line RAW 264.7 and WBC264-9C was purchased from ATCC (Virginia, USA). DMEM media (RAW 264.7) and grown in Eagle's minimum essential medium (WBC264-9C) supplemented with 10\% fetal bovine serum (FBS), sodium bi-carbonate $(1.5 \mathrm{gm} / \mathrm{L})$, $100 \mathrm{U} / \mathrm{mL}$ penicillin, and $100 \mu \mathrm{g} / \mathrm{mL}$ streptomycin at $37^{\circ} \mathrm{C}$ with $5 \% \mathrm{CO}_{2}$ atmosphere according to ATCC recommendations. Cells were treated with $20 \mathrm{ng} / \mathrm{mL}$ GM-CSF (\#NBP2-35066, Novus Biologicals), $20 \mathrm{ng} / \mathrm{mL}$ M-CSF (\#14-8983-62, ThermoFisher), 40 ng/mL IL-4 (\#574306, BioLegend), $1000 \mathrm{IU} / \mathrm{mL}$ IFN $\gamma$ (\#NBP2-35071, Novus Biologicals), $0.5 \mu \mathrm{g} / \mathrm{mL}$ lLipopolysaccharide (\#00-4976-93, ThermoFisher), $25 \mu \mathrm{M}$ cycloheximide (\#0970, R\&D Systems) dissolved in serum-free DMEM. All RAW 264.7 cell experiments were done with cells between passage 4 and passage 8. Cells were exposed to a brief period of serum starvation in serum-free DMEM for $3 \mathrm{~h}$ followed by stimulation with pro-inflammatory stimuli (LPS, GM-CSF, and IFNY), anti-inflammatory stimuli (M-CSF and IL-4), and cycloheximide $(\mathrm{CHX})$ at above-mentioned doses for stated durations.

\section{Western blot analysis}

Cells were harvested and lysed on ice using RIPA lysis and extraction buffer (\# 89901, Thermo Scientific) supplemented with Halt ${ }^{\mathrm{TM}}$ protease and phosphatase inhibitor cocktail (\#78442, Thermo Scientific). Cell lysates were boiled with 2-mercaptoethanol- (\#21985-023, Life Technologies) activated Laemmli sample buffer at $100^{\circ} \mathrm{C}$ for $5 \mathrm{~min}$. In total, 50 microgram of total protein was loaded in each well of a $8 \%$ Bis-Tris gel, run and transferred to the PVDF blotting membrane using a semidry transfer module. After blocking with 5\% skim milk in TBST for an hour at room temperature, membranes were probed overnight at $4{ }^{\circ} \mathrm{C}$ with primary antibodies (anti TSP-4 primary monoclonal Ab (\#sc-390734, Santa Cruz Biotechnology) at 1:100 dilution; anti $\beta$-actin Ab (\#A5316, Sigma-Aldrich) at 1:10000 dilution) followed by HRP antimouse secondary antibodies (\#sc-516102, Santa Cruz Biotechnology and \#1706516, Bio-Rad; respectively) incubation and developed with Pierce ECL western blotting substrate on X-ray films for a time optimal to compare data points in each experiment.

\section{Quantitative real-time RT-PCR analysis}

The total RNA was extracted using TRIzol Reagent (\#15596026, ThermoFisher) followed by cDNA synthesis using SuperScript ${ }^{\mathrm{TM}}$ First-Strand Synthesis System
(\#11904018, ThermoFisher). The TaqMan ${ }^{\oplus}$ probe for Thbs4 (Assay ID\# Mm03003598_s1, ThermoFisher), CD68 (Assay ID\# Mm03047343_m1, ThermoFisher), CD38 (Assay ID\# Mm01220906_m1, ThermoFisher), Egr2 (Assay ID\# Mm00456650_m1, ThermoFisher), Nos2 (Assay ID\# Mm00440502_m1, ThermoFisher), Arg1 (Assay ID\# Mm00475988_m1, ThermoFisher) were used for detecting respective genes expressions with Stx5a (Assay ID\# Mm00502335_m1, ThermoFisher)) and ACTB (Assay ID\# Mm02619580_g1, ThermoFisher) were used as housekeeping gene controls.

\section{Macrophage differentiation and survival assays}

Cells were seeded in 24-well plates at 300,000 cells/well in M1 and M2 differentiation media (\#C-28055, \#C-28056, Promo Cell). Initial attachment of cells was determined after $3 \mathrm{~h}$ using CyQUANT live-cell quantification kits. Cells were kept into M1 and M2 differentiation media for 5 days followed by total live-cell quantification using CyQUANT reagent. Each group of live-cell quantification after 5-day time points was normalized to their respective 3-h initial attachment quantification, and compared to assess cell survival of macrophages from WT or Thbs $4^{-1-}$ or P387TSP-4-KI mice.

\section{BMDM apoptosis assay}

BMDM isolated from WT, Thbs4 $4^{-1-}$, or P387-TSP-4-KI mice were differentiated with $50 \mathrm{ng} / \mathrm{mL}$ GM-CSF for 7 days. BMDM were treated with $0.5 \mu \mathrm{g} / \mathrm{mL}$ LPS in serum-free media for $24 \mathrm{~h}$ followed by qRT-PCR for Bax, Bcl2, and Caspase 3 (Casp3) expression.

For apoptosis assays, BMDM were seeded into 96-well plates (20,000 cells/well) and treated with $0.5 \mu \mathrm{g} / \mathrm{mL}$ LPS for $48 \mathrm{~h}$. Apoptosis was measured using Cell Meter ${ }^{\mathrm{TM}}$ NoWash Live Cell Caspase 3/7 Activity Assay Kits (\#20250, AAT Bioquest). Caspase 3/7 activity data were normalized to the total number of live cells (determined by CyQUANT kit) in each of the respective experimental groups.

\section{In vitro adhesion assays}

Adhesion assays were performed as previously described $^{14,24,25,37,42}$. MPM were isolated from WT, Thbs $4^{-1-}$, and P387-TSP-4-KI mice $72 \mathrm{~h}$ after treatment with $0.25 \mu \mathrm{g} / \mathrm{g}$ LPS, and $5 \times 10^{3}$ cells were added for $1 \mathrm{~h}$ at $37^{\circ} \mathrm{C}$ to wells of 24 -well plates (Corning) pre-coated with fibronectin (Sigma-Aldrich) or without coating.

\section{In vitro migration assays}

MPM were isolated from LPS treated WT, Thbs $4^{-1-}$, and P387-TSP-4-KI mice, and $0.2 \times 10^{6}$ MPM were resuspended in the serum-free DMEM and transferred into the trans-well chambers (Corning, Corning, NY, USA). FBS (20\%) was used as a chemo-attractant in the 
bottom chambers. The cells were incubated at $37^{\circ} \mathrm{C}$ for $4 \mathrm{~h}$, the medium was aspirated, and attached cells were removed from the surface of the upper chamber using Qtips. The plates were frozen at $-80^{\circ} \mathrm{C}$ for $3 \mathrm{~h}$, and DNA from remaining cells was quantified using the CyQUANT reagent (Invitrogen, Carlsbad, CA, USA).

\section{Immunohistochemistry, immunofluorescence, confocal imaging, and quantification of macrophage markers}

Sections of mice peritoneum (three mice of each genotype, with at least two sections of peritoneal tissue from each) were stained with primary rat anti-mouse CD68 antibody (MCA1957B, Bio-Rad), rabbit antimouse CD38 antibody (bs-0979R, Bioss Antibodies), rabbit anti-mouse Egr2 (ab90518, Abcam) antibody using the Vecta Stain ABC Kit. Visualization after staining with the antibodies was performed using a high-resolution slide scanner, Leica Aperio AT2 slide scanner (Leica Microsystems, GmbH, Wetzlar, Germany) was used to scan images of whole slides at $\times 20$ magnification and quantified to determine the percentage of the stained area using Adobe photoshop CS6 (Media Cybernetics). The person performing quantification was blinded to the assignment of animals between groups. For immunofluorescence, rat antimouse CD68 (MCA1957B, Bio-Rad) and goat antihuman TSP-4 (AF2390, R\&D Systems) were used with corresponding secondary antibodies (1:1000). Secondary antibodies were anti-goat NL557 conjugated donkey IgG (NL001 R\&D Systems) and goat polyclonal antibody to rat IgG Alexa Fluor 488 (ab150161, Abcam). Images were taken at a high-resolution confocal microscope (Leica DM 2500) at $\times 63$ magnification. All sections with primary antibodies were incubated for $2 \mathrm{~h}$ at $4{ }^{\circ} \mathrm{C}$ followed by incubating sections in secondary antibodies for $45 \mathrm{~min}$ at $4{ }^{\circ} \mathrm{C}$.

\section{Statistical analysis}

Group size was calculated based on the previous data obtained in mouse models $s^{5,14,24,30}$. Analyses of the data were performed using Sigma Plot Software (Systat Software, San Jose, CA, USA): Student's $t$ test and one-way ANOVA were used to determine the significance of parametric data, and Wilcoxon rank-sum test was used for nonparametric data. The significance level was set at $p=0.05$. The data are presented as mean \pm SEM; the number of biological repeats are listed in each figure legend. Dot plots for each figure are provided as Supplementary Figures.

\section{Results \\ LPS and pro-inflammatory cytokines induce TSP-4 expression in macrophages}

LPS induced TSP-4 in a time-dependent manner in RAW264.7 and BMDM (Fig. 1a). Most TSP-4 was intracellular in both macrophage types (Fig. 1b). In both cell types, both the protein levels and mRNA levels were increased in response to LPS stimulation of cells (Fig. 1a, c). The decreases in protein levels in cells treated with cycloheximide were comparable with untreated cells, also consistent with the transcriptional mechanism or increased RNA stability.

We examined the effects of pro-inflammatory (LPS, IFN $\gamma$, and GM-CSF) and anti-inflammatory stimuli (MCSF and IL-4) on the levels of TSP-4 protein and mRNA in RAW 264.7 cells (Fig. 2a-c) and in BMDM (Fig. 2d-f). BMDM were isolated from mice and cultured in macrophage differentiation media for 7 days. The purity was assessed by flow cytometry using anti-CD11b and F4/ 80 staining and was 93-98\% (Supplementary Fig. 1). Western blot analysis showed a gradual increase in TSP-4 protein levels with pro-inflammatory stimuli LPS, IFN $\gamma$, and GM-CSF. Conversely, TSP-4 protein levels reduced with anti-inflammatory cytokine IL-4 and M-CSF stimulation (Fig. 2 a, b, d, e; Supplementary Fig. 2). Average TSP-4 protein amount was quantified from three independent experiments, and normalized to $\beta$-actin expression as a loading control. Anti-inflammatory stimuli caused significant $(" p<0.05)$ reduction in TSP-4 protein levels (Fig. 2b, d-f; Supplementary Fig. 2). In addition, equal loading and transfer of protein was confirmed by staining the membranes with Ponceau Red (Supplementary Fig. 3).

THBS4 mRNA levels were measured by quantitative RT-PCR (Fig. 2c, f). There was a significant (" $p<0.05)$ increase in THBS4 expression upon stimulation with proinflammatory stimuli and a decrease in THBS4 expression with anti-inflammatory stimuli.

Expression of markers of both pro-inflammatory (CD38 and Nos2, Fig. 3a-d; Supplementary Fig. 4A-D) and tissue-repair (Egr-2 and Arg1, Fig. 3e-h; Supplementary Fig. 4E-H) macrophages was measured in RAW 264.7 cells and BMDM in response to pro-inflammatory and anti-inflammatory stimuli, respectively. Following stimulation with IFN $\gamma(1000 \mathrm{IU} / \mathrm{mL})$, GM-CSF $(20 \mathrm{ng} / \mathrm{mL})$, LPS $(0.5 \mu \mathrm{g} / \mathrm{mL}), \quad$ M-CSF $(20 \mathrm{ng} / \mathrm{mL})$, or IL- $4(40 \mathrm{ng} / \mathrm{mL})$, increased TSP-4 levels were detected (Fig. 2) and correlated with increased CD38 and Nos2 expression. Decrease in TSP-4 levels upon stimulation with anti-inflammatory IL-4 and M-CSF (Fig. 2) was associated with increased Egr-2 and Arg1 expression.

\section{TSP-4 promotes differentiation of macrophages into pro- inflammatory phenotype}

To understand whether TSP-4 promotes the differentiation of macrophages into pro-inflammatory phenotype or whether the increased production of TSP-4 results from differentiation but does not affect the process, BMDM from WT and Thbs $4^{-/-}$mice were stimulated 
A

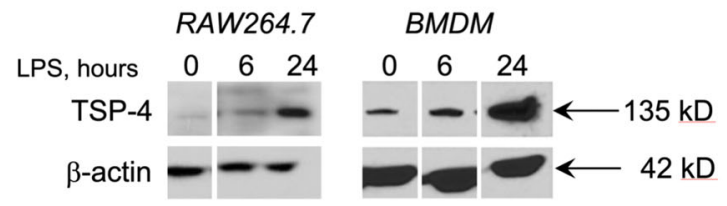

B
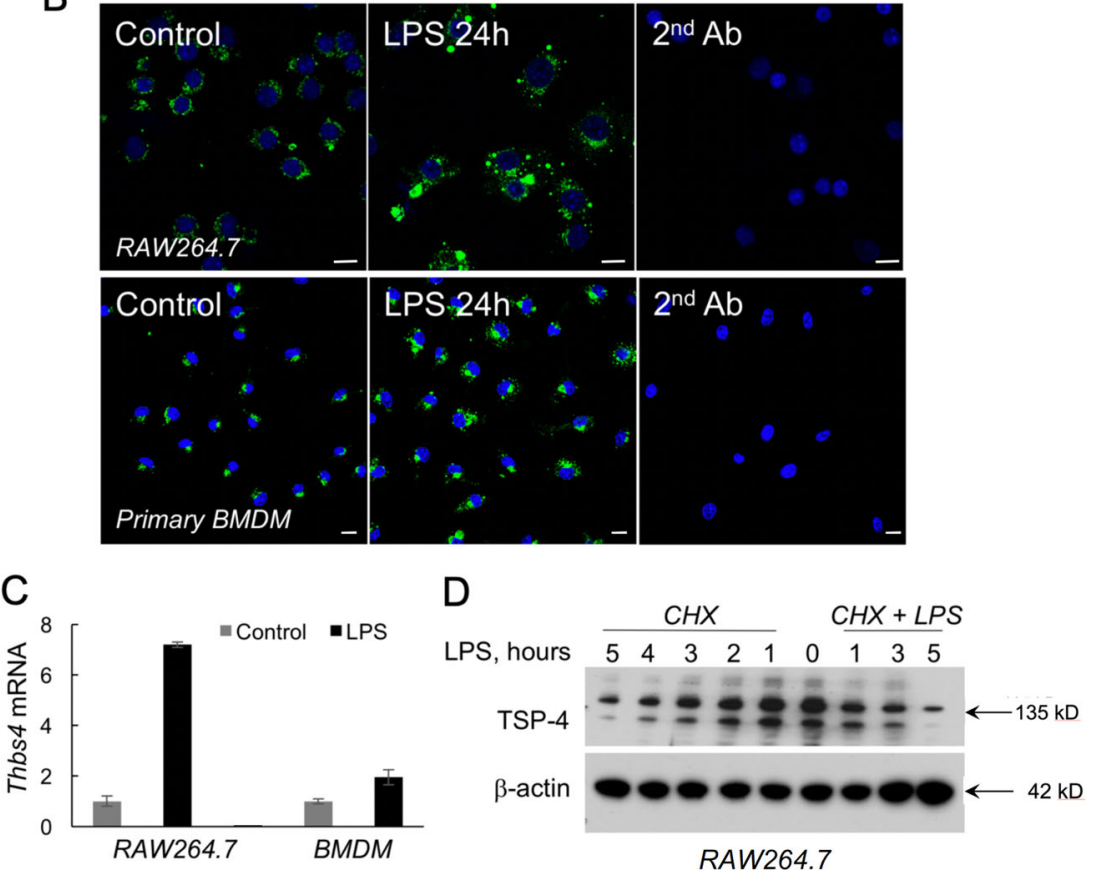

Fig. 1 LPS induces TSP-4 in cultured macrophages. a Cultured macrophage-like RAW264.7 and cells and mouse bone-marrow-derived macrophages (BMDM) were treated with LPS $(0.5 \mu \mathrm{g} / \mathrm{ml}$ for 1-24 h); western blotting with anti-TSP-4 Ab. b Cultured RAW264.7 (upper panels) and BMDM (lower panels) treated with LPS for $24 \mathrm{~h}$ were stained with anti-TSP-4 Ab; green = TSP-4, blue = nuclei, DAPI. Scale bar is $10 \mu \mathrm{m}$. c RAW 264.7 and BMDM cells were treated with LPS $(0.5 \mu \mathrm{g} / \mathrm{mL})$ for $24 \mathrm{~h}$, and qRT-PCR was done (control = PBS treated); $\mathbf{d}$ RAW 264.7 cells were treated with CHX $(25 \mu \mathrm{M})$ for $1-5 \mathrm{~h}$ and $\mathrm{CHX}(25 \mu \mathrm{M})+\mathrm{LPS}(0.5 \mu \mathrm{g} / \mathrm{mL})$ for $1-3 \mathrm{~h}$ followed by western blot detection of TSP-4 ( $\beta$-actin as loading controls). CHX was added at time 0 , followed by addition of LPS.

with LPS $(0.5 \mu \mathrm{g} / \mathrm{mL})$ and IFNY $(1000 \mathrm{IU} / \mathrm{mL})$, and the levels of mRNA of the markers of pro-inflammatory differentiation of macrophages CD38 and Nos2 were measured by real-time PCR (Fig. 4a; Supplementary Fig. 5A). The levels of both markers were significantly decreased in BMDM from Thbs $4^{-1-}$ mice, suggesting that TSP-4 promotes the differentiation into pro-inflammatory phenotype. The basal levels of CD38, a marker of proinflammatory macrophages, was unchanged in Thbs4 ${ }^{-/-}$ mice and increased in P387-TSP4-KI mice (Supplementary Fig. 6). The basal levels of Nos2, another marker of pro-inflammatory macrophages, was unchanged in Thbs $4^{-1-}$ mice (Supplementary Fig. 6B).

BMDM from WT and Thbs $4^{-/-}$mice were incubated with recombinant TSP-4 (rTSP-4, $5 \mu \mathrm{g} / \mathrm{ml})^{14,24,37,49}$ for $6 \mathrm{~h}$, and the expression of markers of pro-inflammatory macrophages was measured by QRT-PCR (Fig. 4b; Supplementary Fig. 5B). rTSP-4 induced a 100 -fold increase in the level of CD38 expression in both WT and Thbs4 ${ }^{-/-}$ cells and a 1000-4000 fold increase in NOS2 expression, suggesting that extracellular TSP-4 promotes proinflammatory polarization of macrophages.

When cultured BMDM from WT and Thbs $4^{-/-}$mice were stimulated with IL- 4 and M-CSF, the levels of both markers were higher in the knockout cells without stimulation and in knockout cells stimulated with IL-4 (Fig. 4c), suggesting that in the absence of TSP-4, polarization into a tissue-repair phenotype increases spontaneously.

\section{TSP-4 regulates the survival of pro-inflammatory macrophages}

Programmed death is a natural fate of pro-inflammatory macrophages and is associated with release of inflammatory signals ${ }^{58-65}$. Knowing that TSP-4 expression promotes pro-inflammatory phenotype of macrophages, we investigated the effect of TSP-4 on cultured macrophage apoptosis. 


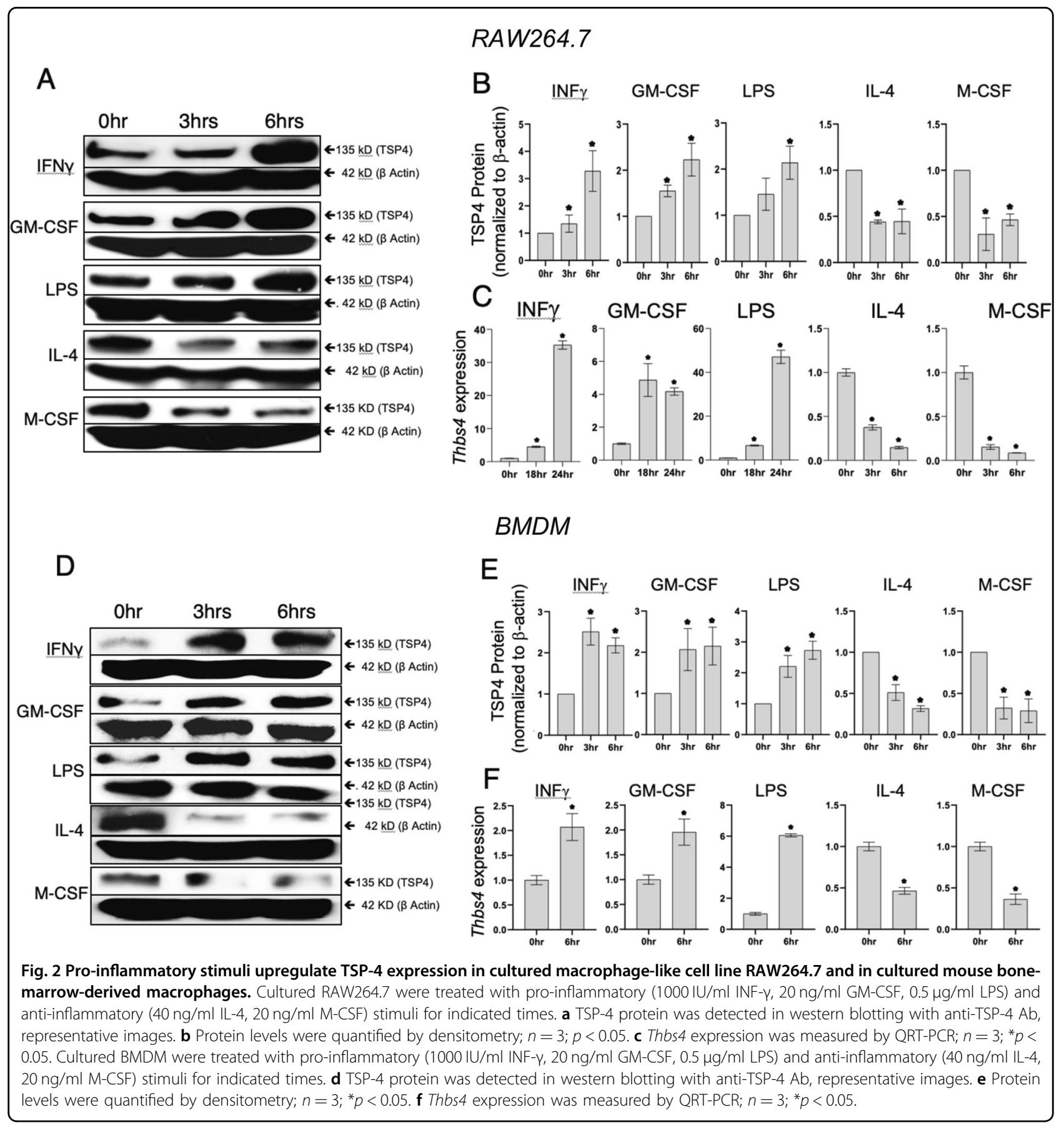

When BMDM from WT, Thbs $4^{-1-}$, and P387-TSP-4KI mice were differentiated in the pro-inflammatory (M1 medium) or tissue-repair differentiation (M2 medium), the survival of cultured pro-inflammatory BMDM but not tissue-repair BMDM was increased in the Thbs $4^{-/-}$cells and decreased in P387-TSP-4-KI cells (Fig. 5a; Supplementary Fig. 7A).

Monocytes were isolated from mouse blood and differentiated in M1 or M2 media. In M1 or M2 media, lack of TSP-4 resulted significantly higher survival of cells, but P387-TSP-4 did not affect cell number (Fig. 5b).

\section{TSP-4 promotes apoptosis in pro-inflammatory macrophages}

Expression of Bax, Bcl2, and Casp 3 and the activity of Caspase 3/7 were measured in the BMDM differentiated into pro-inflammatory macrophages (Fig. 5c, d; Supplementary Fig. 7C). Lower apoptotic activity was 


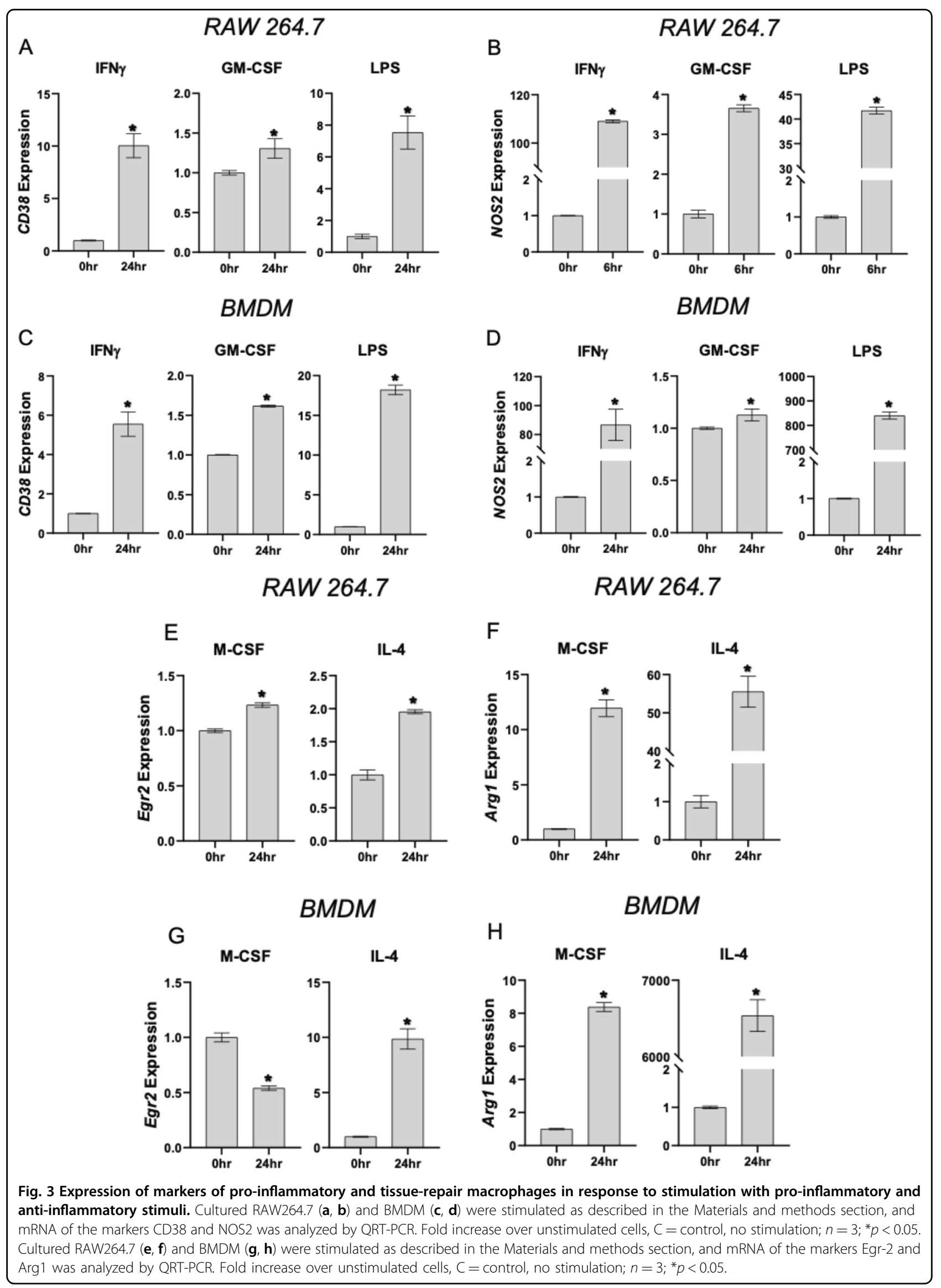



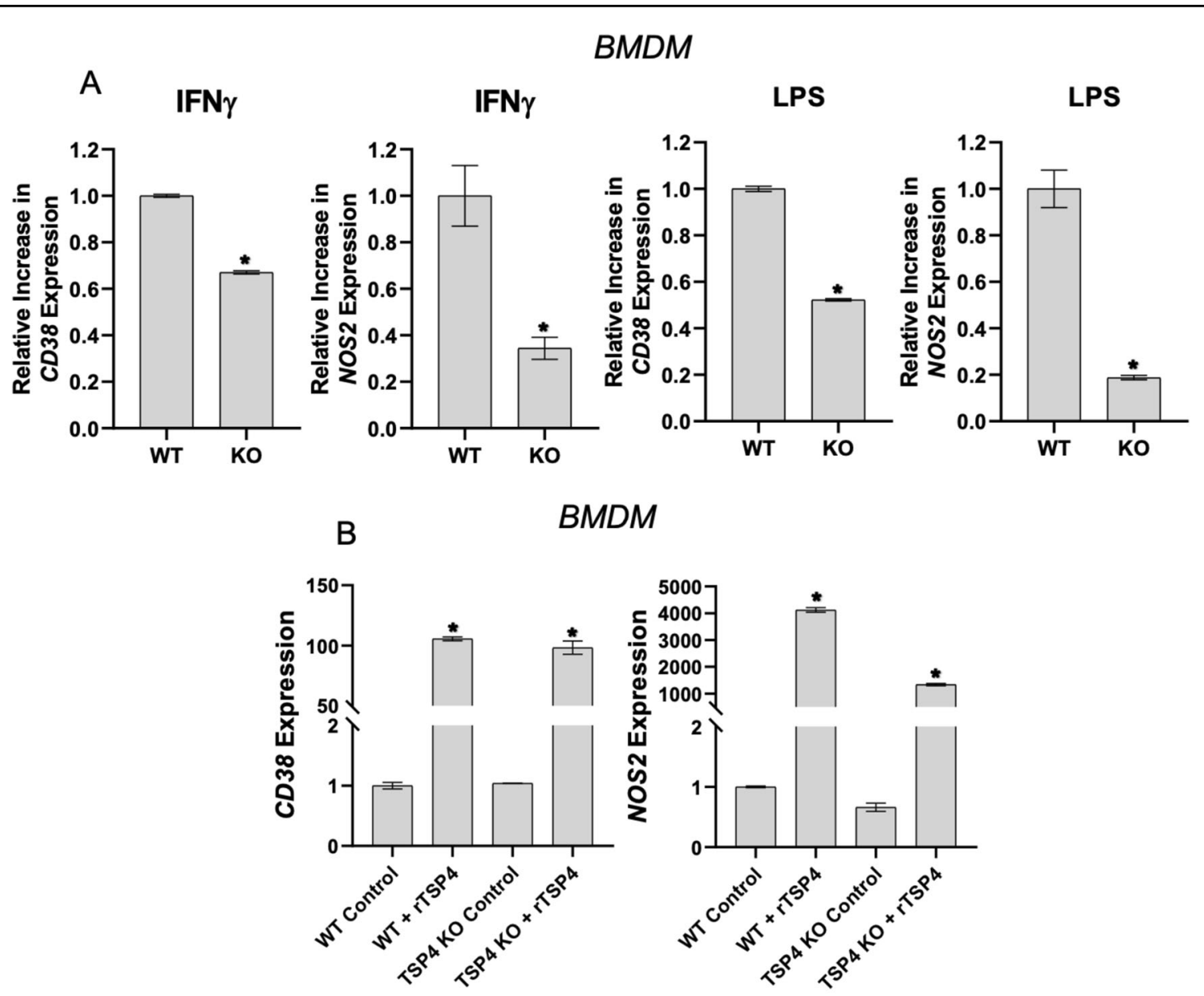

$B M D M$
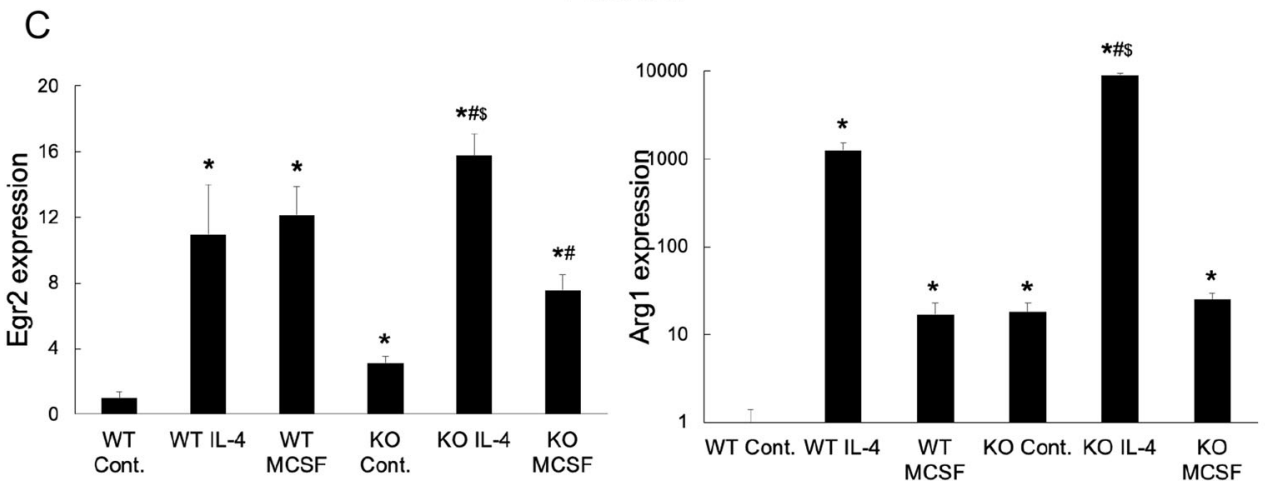

Fig. 4 Deletion of Thbs4 decreases while recombinant TSP-4 upregulates the levels of pro-inflammatory macrophage markers in cultured mouse BMDM. a BMDM were treated with LPS $(0.5 \mu \mathrm{g} / \mathrm{mL})$ and IFNy $(1000 \mathrm{IU} / \mathrm{mL})$ for $6 \mathrm{~h}$, and Nos 2 and CD38 mRNA expression was measured by QRT-PCR; fold decrease is shown on the $y$-axis (control $=1$ in each genotype) $n=3$; ${ }^{*} p<0.05$. $\mathbf{b}$ In all, $5 \mu \mathrm{g} / \mathrm{ml}$ of recombinant TSP-4 (rTSP-4) was used to stimulate BMDM for $6 \mathrm{~h}$, and Nos2 and CD38 mRNA expression was measured by QRT-PCR; $n=3 ;{ }^{*} p<0.05$. c Cultured BMDM from WT and Thbs $4^{-1-}$ mice were stimulated for $24 \mathrm{~h}$ with IL-4 or M-CSF: ${ }^{*} p<0.05$ compared with WT Control (no stimulation); ${ }^{*} p<0.05$ compared with $\mathrm{KO}$ Control (no stimulation), $\$ p<0.05$ compared with identical treatment in WT cells.

detected in $T h b s 4^{-/-}$cells as indicated by decreased $B a x / B c l 2$ ratio, decreased expression of Casp3, and activity of Caspase 3/7 (Fig. 5c and 5d, left panel). In contrast, the activity of Caspase 3/7 was upregulated in response to LPS in P387-TSP-4-KI BMDM (Fig. 5d, right panel). This differential effect is consistent with the higher activity of P387-TSP-4 in other cellular responses $^{24,37,42,49}$. 


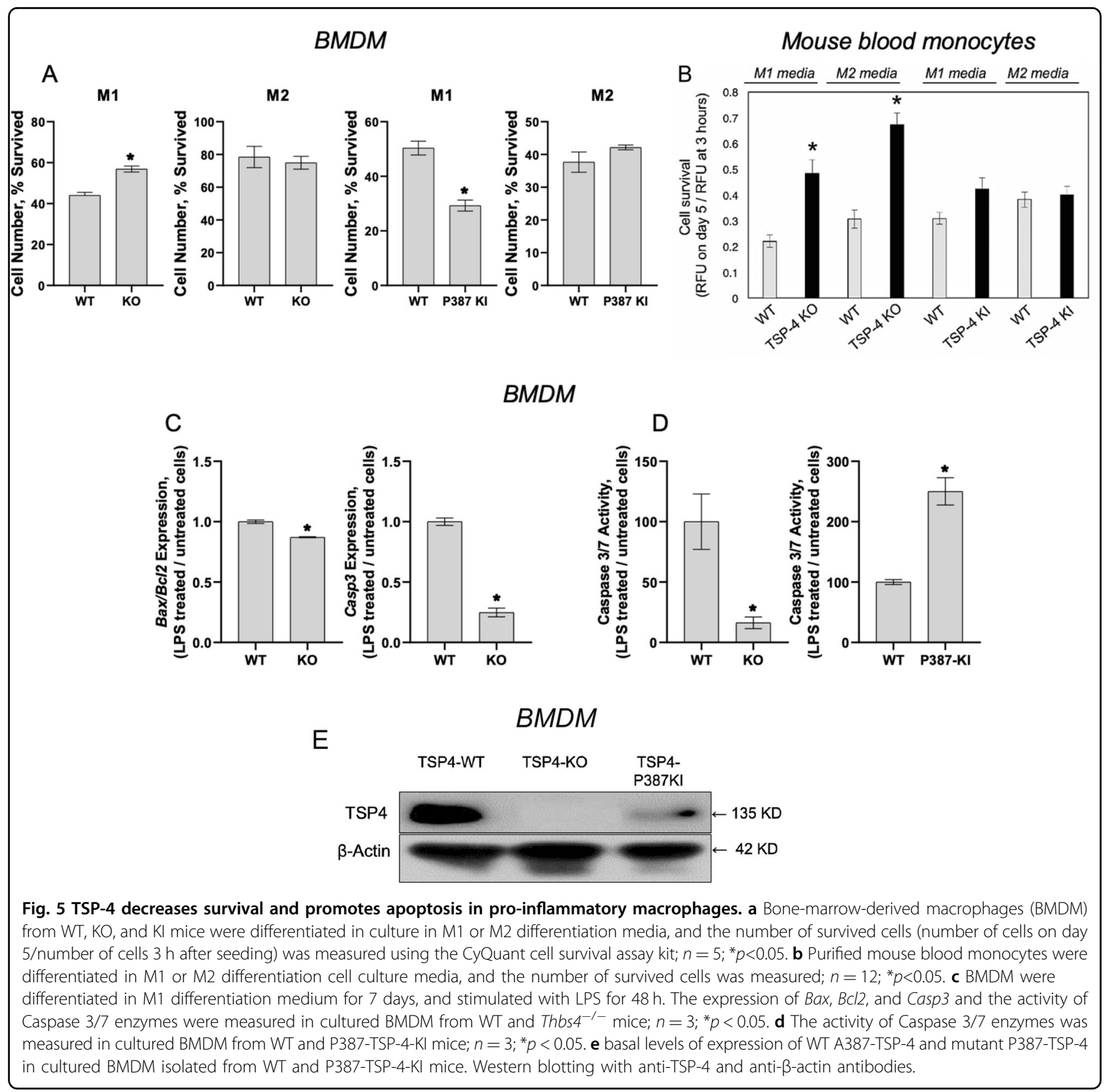

The basal production of TSP-4 protein was not detected in Thbs4 ${ }^{-1-}$ BMDM and was lower in P387-TSP-4-KI cells (Fig. 5e), and thus could not explain the differential effects of TSP-4 variants.

\section{Macrophages in peritoneal cavity and tissue of mice with LPS-induced peritonitis}

To evaluate the expression and the effect of TSP-4 on macrophages in a model of acute inflammation, we induced peritonitis in WT, Thbs $4^{-1}$, and P387-TSP-4-KI mice by IP injection of LPS. Mice were sacrificed $72 \mathrm{~h}$ later, and cells ( $>90 \%$ ) macrophages) were collected by peritoneal lavage and quantified (Fig. 6a; Supplementary Fig. 8). Surprisingly, TSP-4 deletion in the Thbs $4^{-/-}$mice did not reduce the number of macrophages recovered in a saline lavage (free macrophages) compared with WT mice, but we collected fewer macrophages from the cavity of P387-TSP-4-KI mice than from WT mice after LPS-induced peritonitis (Fig. 6a). To find out whether the LPS-induced inflammation affects the expression of TSP-4 in peritoneal tissues and in free macrophages, we assessed the levels of Thbs4 mRNA (Fig. 6b). TSP-4 expression was dramatically decreased in free peritoneal macrophages recovered by lavage and significantly increased in peritoneal tissue of WT mice, 

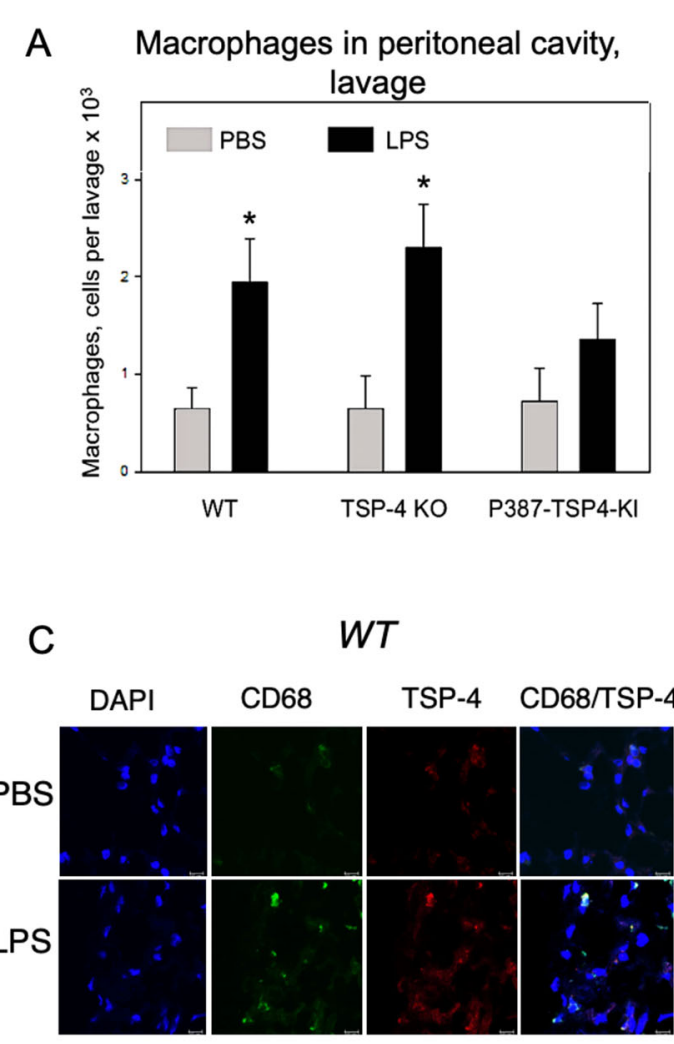

B Mouse Peritoneal

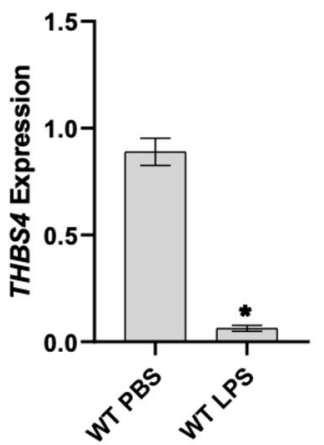

Mouse

Peritoneal Tissues

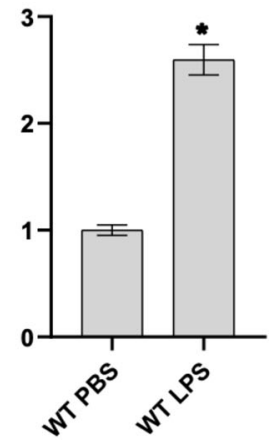

$T S P-4 K I$

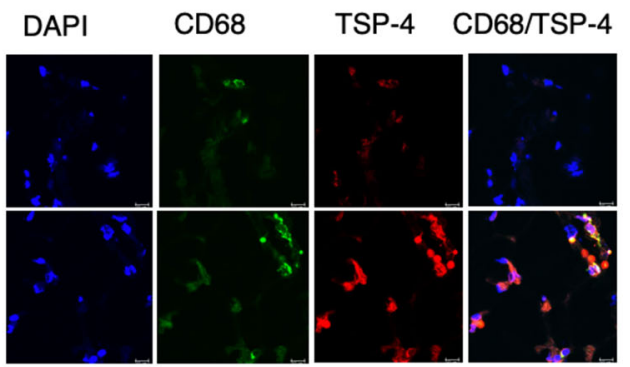

Peritoneum, tissue

Fig. 6 TSP-4 promotes accumulation of macrophages in peritoneal tissue of mice with LPS-induced peritonitis. a The number of macrophages in peritoneal cavity in mice with LPS-induced peritonitis. ${ }^{*} p<0.05, n=5$. b TSP-4 expression in macrophages from the peritoneal cavity lavage (left panel) and in the peritoneal tissue. QRT-PCR, fold increase (RQ) over the values in control mice injected with PBS; $n=3 ;{ }^{*} p<0.05$. c Macrophages and TSP-4 in peritoneal tissue of WT and P387-TSP-4-KI mice with LPS-induced peritonitis. Immunofluorescence; blue = nuclei (DAPI), green $=$ macrophages (anti-CD68), red $=$ TSP-4 (anti-TSP-4). Scale bar is $20 \mu \mathrm{m}$.

suggesting that high levels of TSP-4 in tissue and in macrophages may promote their accumulation in the peritoneal tissue and/or prevent their egress into the cavity.

Immunofluorescence with anti-CD68 and anti-TSP-4 antibodies revealed that TSP-4 protein is associated with macrophages in peritoneal tissue in both WT and P387TSP-4-KI mice (Fig. 6c).

There were no significant changes in monocyte counts in the blood from the two transgenic mice (Supplementary Fig. 9).

\section{TSP-4 increases the number of pro-inflammatory macrophages in peritoneal tissue}

Expression of CD68, a marker of macrophages, was upregulated in peritoneal tissues of WT (Fig. 7a; Supplementary Fig. 10A) and even more dramatically in Thbs $4^{-/-}$ (Fig. 7b) mice with LPS-induced peritonitis. TSP-4 deficiency resulted in higher accumulation of macrophages in peritoneal tissues. In a view of a lack of differences in numbers of macrophages in peritoneal cavity (Fig. 6a) and the equal numbers of macrophages in blood
(Supplementary Fig. 5), this suggested the effect of TSP-4 on macrophage survival in tissues, consistent with our observations in cultured macrophages. The expression of the marker of pro-inflammatory macrophages CD38 was

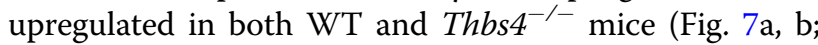
Supplementary Fig. 10A, B), but the expression of Egr-2, a marker of tissue-repair macrophages, was decreased (Fig. 7a), suggesting that most macrophages retained in the peritoneal tissue are pro-inflammatory. Consistent with the difference between WT and Thbs $4^{-/-}$mice and the P387-TSP-4, P387-TSP-4 reduced the accumulation of macrophages in peritoneal tissue (Fig. 7c; Supplementary Fig. 10C), suggesting more profound effect on their survival.

P387-TSP-4 is more active in supporting the adhesion of monocytes and macrophages

We used murine macrophage-like cell line RAW264.7 to assess the effect of A387-TSP-4 and P387-TSP-4 on macrophage adhesion and migration (Fig. 7). RAW264.7 cells migrated less on rTSP-4 as a substrate, and P387- 


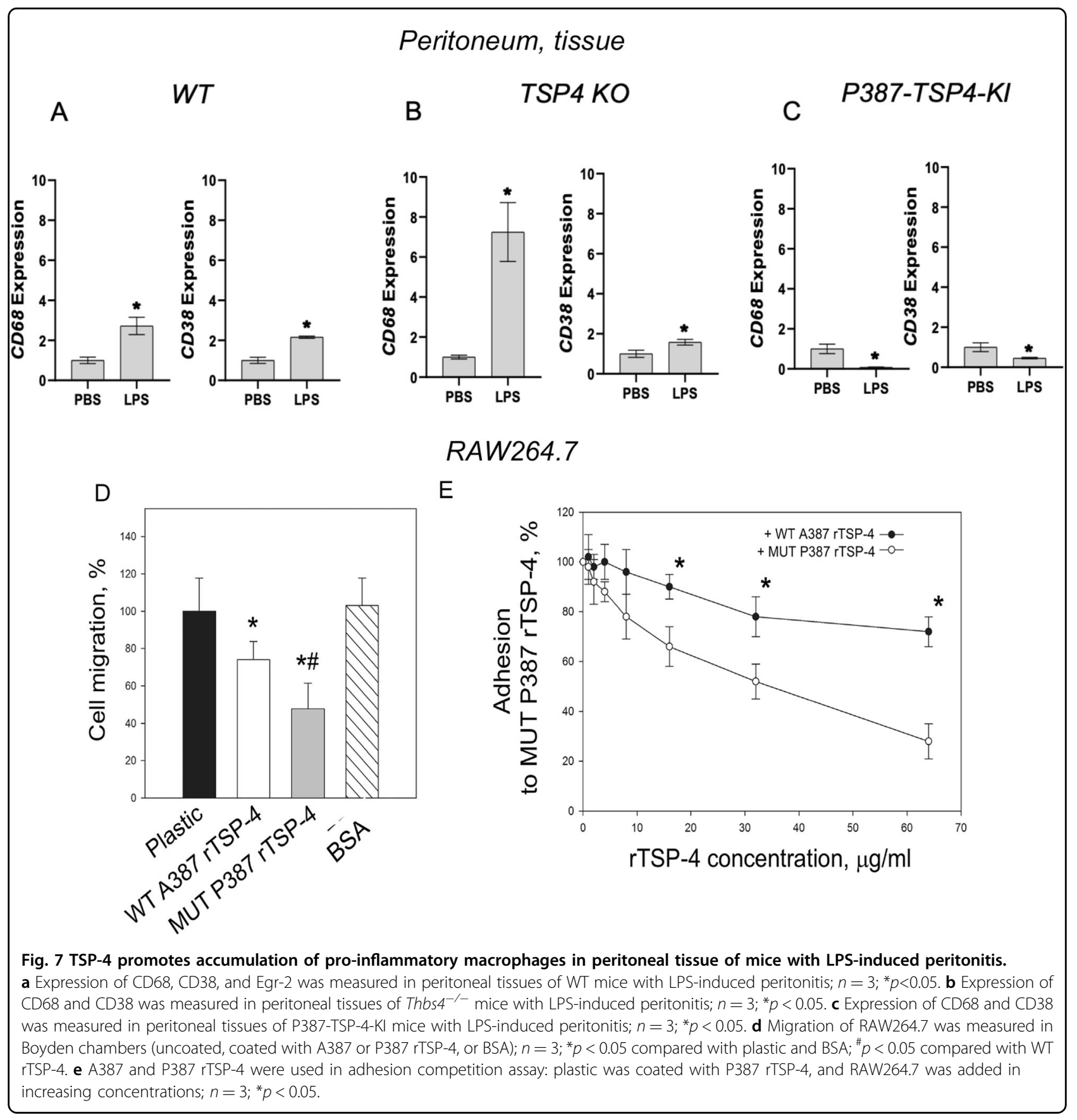

TSP-4 further decreased their migration (Fig. 7a). RAW264.7 adhered significantly better to P387-TSP-4 (Fig. 7b), although both A387 and P387-TSP-4 supported the adhesion of macrophage-like cells.

\section{Discussion}

High expression of TSP-4 in remodeling tissues, particularly in heart disease and cancer ${ }^{5-12,14-29}$, suggested that this matricellular protein may regulate fibrosis and angiogenesis. The effects of TSP-4 on matrix remodeling has been demonstrated in Thbs $4^{-1-}$ mice by us and others $^{5-7,30}$, and we recently reported that TSP-4 is proangiogenic $^{24,25}$ in contrast to the prominent role of TSP-1 as an anti-angiogeneic protein ${ }^{2,66,67}$. Tissue remodeling is associated with inflammation, and we reported that TSP-4 deficiency results in reduced inflammation in atherosclerotic lesions in $A p o E^{-/-}$mice: the number of macrophages in the atherosclerotic lesion and the local vascular inflammation were reduced in $T h b s 4^{-1-} / A p o E^{-/-}$ mice $^{14}$. To investigate the roles of TSP -4 and its variants 
in inflammation, we examined the effects of TSP-4 on cultured macrophages and on macrophages in an LPSinduced mouse peritonitis model.

Several agents that are known to promote proinflammatory differentiation of macrophages (LPS, GM$\mathrm{CSF}$, and $\mathrm{INF}^{68}$ ) or tissue-repair differentiation (IL-4 ${ }^{68}$ and $\mathrm{M}-\mathrm{CSF}^{69}$ ) were used to stimulate cultured RAW264.7 and BMDM. LPS that was also used to induce peritonitis, increased TSP-4 production by macrophages in a timedependent manner. mRNA of Thbs 4 was also upregulated, and production of the protein was efficiently blocked by cycloheximide, suggesting transcriptional regulation or reduced RNA stability. The newly synthesized protein accumulated in vesicle-like structures inside the cells, and was not efficiently secreted into the medium or matrix (not shown). Intracellular functions have been reported for $\mathrm{TSPs}^{7}$. Finding of increased amounts of intracellular TSP-4 suggested that such intracellular functions of TSP-4 may be activated by the treatment or that macrophages accumulate protein in vesicles that may be released in specific tissues where an inflammation response has been triggered. Alternatively, the intracellular protein could reflect uptake of the secreted TSP-4 by the cells. When exogenous recombinant TSP-4 was used in experiments with cultured BMDM, it efficiently induced expression of markers of pro-inflammatory macrophages, suggesting that thie pro-inflammatory effect of TSP-4 on macrophages depends on TSP-4 interactions with cellular receptors upon TSP-4 secretion into ECM.

All pro-inflammatory signals that resulted in proinflammatory differentiation with increased expression of CD38 and Nos2 (markers of pro-inflammatory macrophages) and decreased expression of Egr-2 and Arg1 (markers of tissue-repair macrophages) also increased TSP-4 expression and production. To the contrary, antiinflammatory signals promoting the tissue-repair differentiation of macrophages (decreased CD38 and Nos2 and increased Egr-2 and Arg1) decreased the expression of Thbs 4 and the production of the TSP-4 protein. Thus, our results suggested a novel role for TSP-4 in inflammation: support of pro-inflammatory functions of macrophages. When BMDM from Thbs $4^{-1-}$ mice were stimulated with pro-inflammatory signals, the levels of markers of proinflammatory macrophages were decreased, demonstrating that TSP-4 actively promotes macrophage differentiation into pro-inflammatory phenotype.

We analyzed cultured primary BMDM and blood monocytes, and found that survival of both cell types was higher in Thbs $4^{-1-}$ macrophages cultured in the M1 medium. P387-TSP-4 in macrophages from P387-TSP4KI mice significantly decreased their survival. Knowing that TSP-4 expression is associated with pro-inflammatory macrophages, we hypothesized that the regulation of macrophage number in the peritonitis model may be associated with their ability to differentiate into the proinflammatory phenotype and to commit to apoptosis, a process closely associated with pro-inflammatory differentiation. Pro-inflammatory macrophages produce and release inflammatory stimuli, and this release is associated with their transition to apoptosis ${ }^{58-65}$. Both our in vivo and in vitro results suggested that TSP-4 is needed for completion of pro-inflammatory differentiation of macrophages, their transition into apoptosis, and their release of pro-inflammatory signals. This sequence of events was observed using cultured RAW264.7 and BMDM. TSP-4 $\mathrm{KO}$ reduced caspase 3 gene expression and activity of caspase 3/caspase 7 , as well as the ratio of expressed Bax/ $\mathrm{Bcl} 2$ in BMDM in response to LPS stimulation, confirming that TSP-4 promotes apoptosis in proinflammatory macrophages. P387-TSP-4 BMDM from P387-TSP-4-KI mice had increased expression of apoptotic markers compared with BMDM isolated from WT mice, consistent with higher activity of this TSP-4 variant in many cellular effects and interactions that we previously reported.

TSP-4 increased accumulation of macrophages in peritoneal tissues, presumably by increasing their adhesive properties, reducing the macrophage migration as was demonstrated in cultured cells, and, as a result, decreasing the egress of macrophages from the peritoneal tissue into the cavity. LPS injection significantly increased the number of macrophages recovered in the lavage of the peritoneal cavity of WT mice and Thbs $4^{-1-}$ mice, but, in P387-TSP-4-KI mice, the number of recovered macrophages was not increased by LPS compared with the saline control. Free peritoneal macrophages recovered by lavage produced very little TSP-4, while the levels of TSP-4 mRNA and protein were increased in peritoneal tissue as was detected by QRTPCR and immunofluorescence. TSP-4 production was associated with CD68-positive cells, macrophages, in the tissue. It remains an open question whether some blood monocytes are predisposed to produce larger amounts of TSP-4, restricting their egress into the peritoneal cavity, and whether a fraction of blood monocytes is unable to produce TSP-4 and thus, macrophages differentiated from these blood monocytes egress into the cavity more easily.

The production of TSP-4 by the blood cells has not been previously reported, and the ability of macrophages to produce TSP-4 protein has not been recognized. However, as we report here, we identified several proinflammatory agonists that stimulate macrophages to produce TSP-4 both in cell culture and in vivo.

P387-TSP-4 is a SNP variant of TSP-4 that is carried by $>30 \%$ of North American population ${ }^{18}$. In our previous studies of this TSP-4 variant in vitro in cell culture, and 
in vivo in a mouse model, we found that P387-TSP-4 was more active in all cellular effects and interactions tested, and was less susceptible to proteolytic degrada$\operatorname{tion}^{5,14,24,25,30,37,42,49}$. Thus, the lack of increased macrophage egress into the peritoneal cavity of P387-TSP-4-KI mice was surprising and suggested that P387-TSP-4 prevented macrophage egress from tissues leading to increased accumulation in peritoneal tissues due to its higher adhesive properties than the WT, A387-TSP4 form.

TSP-4 supports the adhesion of leukocytes ${ }^{14,37}$ and macrophages specifically ${ }^{14}$. We have performed adhesion and migration assays with macrophage-like cells RAW264.7, and demonstrated that both A387- and P387TSP-4 support the adhesion of macrophages and reduce their migratory activity, but, as was expected based on our previous publications ${ }^{24,37,42,49}$, P387-TSP-4 is more effective in these functions.

Although the accumulation of macrophages in peritoneal tissue was increased in response to LPS in all three mouse strains, WT expressing the A387-TSP-4 isoform, Thbs4 ${ }^{-1-}$, and P387-TSP-4-KI, the relative increase in macrophage accumulation (in comparison with mice receiving PBS) was surprisingly higher in Thbs $4^{-/-}$mice and significantly lower in P387-TSP-4-Ki mice. Since the number of monocytes in blood was not significantly different between the three genotypes, and the number of macrophages in peritoneal cavity could not account for any differences in macrophage accumulation in tissues, these results suggested that TSP-4 levels might affect survival of macrophages in tissues. In addition to the effect of TSP-4 on CD68 levels, CD38 levels also followed the trend, suggesting that TSP-4 acts on proinflammatory macrophages rather than tissue-repair macrophages. Similar to other TSP-4 functions, the P387 variant of TSP-4 was more active in exerting these effects on macrophages, promoting inflammation, accumulation of macrophages in tissue, and their transition to apoptosis that allows macrophages to release proinflammatory stimuli and sustain a pro-inflammatory environment.

The association of TSP- 4 with tissue inflammation and pro-inflammatory differentiation of macrophages was observed in vivo, in peritonitis model, as well as in cultured macrophages. TSP-4 carries out a dual role in inflammation by facilitating macrophage adhesion and promoting the pro-apoptotic response of macrophages at sites of tissue inflammation. This association suggests a new and unanticipated role for TSP-4 in inflammation: TSP-4 and its P387 variant are produced by macrophages in response to inflammatory stimuli and regulate the accumulation of macrophages in tissues and their proinflammatory functions.

\section{Acknowledgements}

This work has been supported by R01 HL117216 (E.F.P. and O.S.A.) and R01 CA177771 (O.S.A.).

Conflict of interest

The authors declare that they have no conflict of interest.

\section{Publisher's note}

Springer Nature remains neutral with regard to jurisdictional claims in published maps and institutional affiliations.

Supplementary Information accompanies this paper at (https://doi.org/ 10.1038/s41419-020-2237-2).

Received: 28 May 2019 Revised: 25 September 2019 Accepted: 7 October 2019

Published online: 23 January 2020

\section{References}

1. Adams, J. C. \& Lawler, J. The thrombospondins. Int J. Biochem. Cell Biol. 36, 961 (2004).

2. Adams, J. C. \& Lawler, J. The thrombospondins. Cold Spring Harb. Perspect. Biol. 3. a009712 (2011).

3. Tan, F. L. et al. The gene expression fingerprint of human heart failure. Proc Natl Acad. Sci. USA 99, 11387 (2002).

4. Mustonen, E. et al. Thrombospondin-4 expression is rapidly upregulated by cardiac overload. Biochem. Biophys. Res. Commun. 373, 186 (2008).

5. Frolova, E. G. et al. Thrombospondin-4 regulates fibrosis and remodeling of the myocardium in response to pressure overload. FASEB J. 26, 2363 (2012).

6. Cingolani, O. H. et al. Thrombospondin-4 is required for stretch-mediated contractility augmentation in cardiac muscle. Circ. Res. 109, 1410 (2011).

7. Lynch, J. M. et al. A thrombospondin-dependent pathway for a protective ER stress response. Cell 149, 1257 (2012).

8. Cho, J. Y. et al. Gene expression signature-based prognostic risk score in gastric cancer. Clin. Cancer Res. 17, 1850 (2011).

9. D'Errico, M. et al. Genome-wide expression profile of sporadic gastric cancers with microsatellite instability. Eur. J. Cancer 45, 461 (2009).

10. Singh, D. et al. Gene expression correlates of clinical prostate cancer behavior. Cancer Cell 1, 203 (2002).

11. Ma, X. J. et al. A two-gene expression ratio predicts clinical outcome in breast cancer patients treated with tamoxifen. Cancer Cell 5, 607 (2004).

12. Curtis, C. et al. The genomic and transcriptomic architecture of 2,000 breast tumours reveals novel subgroups. Nature 486, 346 (2012).

13. Lu, X., Wang, Z. C., Iglehart, J. D., Zhang, X. \& Richardson, A. L. Predicting features of breast cancer with gene expression patterns. Breast Cancer Res. Treat. 108, 191 (2008)

14. Frolova, E. G. et al. Thrombospondin-4 regulates vascular inflammation and atherogenesis. Circ. Res. 107, 1313 (2010).

15. Wessel, J., Topol, E. J., Ji, M., Meyer, J. \& McCarthy, J. J. Replication of the association between the thrombospondin-4 A387P polymorphism and myocardial infarction. Am. Heart J. 147, 905 (2004).

16. McCarthy, J. J. et al. Large scale association analysis for identification of genes underlying premature coronary heart disease: cumulative perspective from analysis of 111 candidate genes. J. Med. Genet. 41, 334 (2004).

17. Wilsgaard, T. et al. Clinically significant novel biomarkers for prediction of first ever myocardial infarction: the Tromso Study. Circ. Cardiovasc. Genet. 8, 363 (2015).

18. Topol, E. J. et al. Single nucleotide polymorphisms in multiple novel thrombospondin genes may be associated with familial premature myocardial infarction. Circulation 104, 2641 (2001).

19. Yamada, Y. et al. Prediction of the risk of myocardial infarction from polymorphisms in candidate genes. N. Engl. J. Med. 347, 1916 (2002).

20. Kato, T. Y. A., Murase, Y., Hirashiki, A., Noda, A. \& Yamada, Y. Specific gene polymorphisms could be risk factors for coronary artery disease in individuals with or without hypertention. Circulation (Suppl.) 108, IV-712 (2003). 
21. Cui, J. et al. Gender dependent association of thrombospondin-4 A387P polymorphism with myocardial infarction. Arterioscler. Thromb. Vasc. Biol. 24, e183 (2004)

22. Cui, J. et al. Thrombospondin-4 1186G>C (A387P) is a sex-dependent risk factor for myocardial infarction: a large replication study with increased sample size from the same population. Am. Heart J. 152, 543 e541 (2006).

23. Kirk, J. A. \& Cingolani, O. H. Thrombospondins in the transition from myocardial infarction to heart failure. J. Mol. Cell Cardiol. 90, 102 (2016).

24. Muppala, S. et al. Proangiogenic properties of thrombospondin-4. Arterioscler. Thromb. Vasc. Biol. 35, 1975 (2015).

25. Muppala, S. et al. Thrombospondin-4 mediates TGF-beta-induced angiogenesis. Oncogene 36, 5189 (2017).

26. Turashvili, G. et al. Novel markers for differentiation of lobular and ductal invasive breast carcinomas by laser microdissection and microarray analysis. BMC Cancer 7, 55 (2007)

27. McCart Reed, A. E. et al. Thrombospondin-4 expression is activated during the stromal response to invasive breast cancer. Virchows Arch. 463, 535 (2013).

28. Forster, S., Gretschel, S., Jons, T., Yashiro, M. \& Kemmner, W. THBS4, a novel stromal molecule of diffuse-type gastric adenocarcinomas, identified by transcriptome-wide expression profiling. Mod. Pathol. 24, 1390 (2011).

29. Su, F. et al. Over-expression of thrombospondin 4 correlates with loss of miR142 and contributes to migration and vascular invasion of advanced hepatocellular carcinoma. Oncotarget 8, 23277 (2017).

30. Frolova, E. G. et al. Control of organization and function of muscle and tendon by thrombospondin-4. Matrix Biol. 37, 35 (2014).

31. Vanhoutte, D. et al. Thrombospondin expression in myofibers stabilizes muscle membranes. elife 5, 17589 (2016).

32. Eroglu, C. et al. Gabapentin receptor alpha2delta-1 is a neuronal thrombospondin receptor responsible for excitatory CNS synaptogenesis. Cell 139, 380 (2009).

33. Yang, $\mathrm{H}$. J. et al. Thrombospondin-4 promotes neuronal differentiation of NG2 cells via the ERK/MAPK pathway. J. Mol. Neurosci. 60, 517 (2016).

34. Benner, E. J. et al. Protective astrogenesis from the SVZ niche after injury is controlled by Notch modulator Thbs4. Nature 497, 369 (2013).

35. Andersson, D. et al. Plasticity response in the contralesional hemisphere after subtle neurotrauma: gene expression profiling after partial deafferentation of the hippocampus. PLOS ONE 8, e70699 (2013).

36. Girard, F., Eichenberger, S. \& Celio, M. R. Thrombospondin 4 deficiency in mouse impairs neuronal migration in the early postnatal and adult brain. Mol Cell Neurosci. 61, 176 (2014).

37. Pluskota, E. et al. Mechanism and effect of thrombospondin-4 polymorphisms on neutrophil function. Blood 106, 3970 (2005).

38. Brody, M. J. et al. Defective flux of thrombospondin-4 through the secretory pathway impairs cardiomyocyte membrane stability and causes cardiomyopathy. Mol. Cell Biol. 38, e00114 (2018).

39. Congote, L. F., Difalco, M. R. \& Gibbs, B. F. The C-terminal peptide of thrombospondin-4 stimulates erythroid cell proliferation. Biochem. Biophys. Res. Commun. 324, 673 (2004).

40. Park, J. et al. Central mechanisms mediating thrombospondin-4-induced pain states. J. Biol. Chem. 291, 13335 (2016).

41. Crosby, N. D. et al. Thrombospondin-4 and excitatory synaptogenesis promote spinal sensitization after painful mechanical joint injury. Exp. Neurol. 264, 111 (2015).

42. Stenina, O. I. et al. Thrombospondin-4 and its variants: expression and differential effects on endothelial cells. Circulation 108, 1514 (2003).

43. Dunkle, E. T., Zaucke, F. \& Clegg, D. O. Thrombospondin-4 and matrix threedimensionality in axon outgrowth and adhesion in the developing retina. Exp. Eye Res. 84, 707 (2007)

44. Narouz-Ott, L., Maurer, P., Nitsche, D. P., Smyth, N. \& Paulsson, M. Thrombospondin-4 binds specifically to both collagenous and non- collagenous extracellular matrix proteins via its C-terminal domains. J. Biol. Chem. 275, 37110 (2000).

45. Kim, D. S. et al. Thrombospondin-4 contributes to spinal sensitization and neuropathic pain states. J. Neurosci. 32, 8977 (2012).

46. Subramanian, A. \& Schilling, T. F. Thrombospondin-4 controls matrix assembly during development and repair of myotendinous junctions. elife 3, e02372 (2014).

47. Pan, B. et al. Thrombospondin-4 divergently regulates voltage-gated $\mathrm{Ca}^{2+}$ channel subtypes in sensory neurons after nerve injury. Pain 157, 2068 (2016).

48. Arber, S. \& Caroni, P. Thrombospondin-4, an extracellular matrix protein expressed in the developing and adult nervous system promotes neurite outgrowth. J. Cell Biol. 131, 1083 (1995).

49. Stenina, O. I. et al. Polymorphisms A387P in thrombospondin-4 and N700S in thrombospondin-1 perturb calcium binding sites. FASEB J. 19, 1893 (2005).

50. Brody, M. J. et al. Dissection of thrombospondin-4 domains involved in intracellular adaptive endoplasmic reticulum stress-responsive signaling. Mol. Cell Biol. 36, 2 (2016).

51. Murray, P. J. \& Wynn, T. A. Protective and pathogenic functions of macrophage subsets. Nat. Rev. Immunol. 11, 723 (2011).

52. Wynn, T. A., Chawla, A. \& Pollard, J. W. Macrophage biology in development, homeostasis and disease. Nature 496, 445 (2013).

53. Colin, S., Chinetti-Gbaguidi, G. \& Staels, B. Macrophage phenotypes in atherosclerosis. Immunol. Rev. 262, 153 (2014).

54. Porta, C., Riboldi, E., Ippolito, A. \& Sica, A. Molecular and epigenetic basis of macrophage polarized activation. Semin. Immunol. 27, 237 (2015).

55. Ginhoux, F., Schultze, J. L., Murray, P. J., Ochando, J. \& Biswas, S. K. New insights into the multidimensional concept of macrophage ontogeny, activation and function. Nat. Immunol. 17, 34 (2016).

56. Murray, P. J. Macrophage polarization. Annu. Rev. Physiol. 79, 541 (2017).

57. Benoit, M., Desnues, B. \& Mege, J. L. Macrophage polarization in bacterial infections. J. Immunol. 181, 3733 (2008).

58. Kockx, M. M. Apoptosis in the atherosclerotic plaque: quantitative and qualitative aspects. Arterioscler. Thromb. Vasc. Biol. 18, 1519 (1998).

59. Kockx, M. M. et al. Cell composition, replication, and apoptosis in atherosclerotic plaques after 6 months of cholesterol withdrawal. Circ. Res. 83, 378 (1998).

60. Kockx, M. M. et al. Apoptosis and related proteins in different stages of human atherosclerotic plaques. Circulation 97, 2307 (1998).

61. Kockx, M. M. \& Herman, A. G. Apoptosis in atherogenesis: implications for plaque destabilization. Eur. Heart J. 19(Suppl G), G23 (1998).

62. Kolodgie, F. D. et al. Localization of apoptotic macrophages at the site of plaque rupture in sudden coronary death. Am. J. Pathol. 157, 1259 (2000).

63. Soler, C. et al. Lipopolysaccharide-induced apoptosis of macrophages determines the up-regulation of concentrative nucleoside transporters Cnt1 and Cnt2 through tumor necrosis factor-alpha-dependent and -independent mechanisms. J. Biol. Chem. 276, 30043 (2001).

64. Tabas, I. Macrophage death and defective inflammation resolution in atherosclerosis. Nat. Rev. Immunol. 10, 36 (2010).

65. Xaus, J. et al. LPS induces apoptosis in macrophages mostly through the autocrine production of TNF-alpha. Blood 95, 3823 (2000).

66. Lawler, P. R. \& Lawler, J. Molecular basis for the regulation of angiogenesis by thrombospondin-1 and -2. Cold Spring Harb. Perspect. Med. 2, a006627 (2012).

67. Lawler, J. Thrombospondin-1 as an endogenous inhibitor of angiogenesis and tumor growth. J. Cell Mol. Med. 6, 1 (2002).

68. Shapouri-Moghaddam, A. et al. Macrophage plasticity, polarization, and function in health and disease. J. Cell Physiol. 233, 6425 (2018).

69. Hamilton, T. A., Zhao, C., Pavicic, P. G. Jr \& Datta, S. Myeloid colonystimulating factors as regulators of macrophage polarization. Front. Immunol. 5, 554 (2014). 